Available online at http://jurnal.stmikroyal.ac.id/index.php/jurteksi

\title{
PERBANDINGAN ALGORITMA KLASIFIKASI SUPPORT VECTOR MACHINE DAN NAIVE BAYES PADA IMBALANCE DATA
}

\author{
Chika Enggar Puspita ${ }^{1 *}$, Oktariani Nurul Pratiwi ${ }^{1}$, Edi Sutoyo ${ }^{1}$ \\ ${ }^{1}$ Sistem Informasi, Telkom University \\ email: *chikapuspita@student.telkomuniversity.ac.id
}

\begin{abstract}
Question classification is a computer science system, which aims to analyze questions and can label each question based on existing categories. Questions can be collected from several materials or topics that are many and different. Therefore, the researcher intends to create a classification system for quiz questions Data Warehouse and Business Intelligence which can be grouped into topics Data Warehouse, Business Intelligence, Data Analytics, and Performance Measurement. One way to solve this problem is by approach machine learning. In this study, researchers used a comparison of machine learning algorithms, namely the algorithm NaïveBayes and SupportVectorMachine using SMOTE and methods Cross-Validation The results of this study show the best accuracy results and are very helpful. The results obtained in the method cross-validation before SMOTE resulted in an accuracy rate of $82.02 \%$ for the results after going through the SMOTE stage of $94.79 \%$ on the algorithm Naïve Bayes, while the algorithm SupportVectorMachine get accuracy of $81.39 \%$ in the process before SMOTE for the results after going through SMOTE of $96.52 \%$.
\end{abstract}

Keywords: Cross-Validation; Machine Learning; Naive Bayes; Support Vector Machine; Question Classification

\begin{abstract}
Abstrak: Klasifikasi pertanyaan merupakan sebuah sistem ilmu komputer, yang bertujuan untuk menganalisis pertanyaan serta dapat memberi label pada setiap pertanyaan berdasarkan kategori yang ada. Pertanyaan soal dapat dikumpulkan dari beberapa materi atau topik yang banyak dan berbeda. Oleh karena itu, bermaksud untuk membuat sistem klasifikasi pertanyaan soal kuis Data Warehouse dan Business Intelligence yang dapat dikelompokkan menjadi topik Data Warehouse, Business Intelligence, Data Analitik, dan Pengukuran Kinerja. Cara yang dapat dilakukan untuk permasalahan ini dengan menggunakan pendekatan MachineLearning. Pada penelitian kali ini menggunakan perbandingan algoritma MachineLearning yaitu algoritma Nä̈veBayes dan SupportVectorMachine menggunakan metode SMOTE dan Cross-Validation. Hasil penelitian ini menunjukkan hasil akurasi yang terbaik dan sangat membantu. Hasil yang diperoleh pada metode cross-validation sebelum SMOTE menghasilkan tingkat akurasi sebesar 82.02\% untuk hasil sesudah melalui tahap SMOTE sebesar $94.79 \%$ pada algoritma Naïve Bayes, sedangkan pada algoritma Support Vector Machine menghasilkan akurasi sebesar pada proses sebelum SMOTE 81.39\% untuk hasil sesudah melalui SMOTE sebesar 96.52\%.
\end{abstract}

Kata kunci: Klasifikasi Pertanyaan; Pembelajaran Mesin; Naive Bayes; Support Vector Machine; Cross-Validation 
Available online at http://jurnal.stmikroyal.ac.id/index.php/jurteksi

\section{PENDAHULUAN}

\section{E-learning atau Electronic-} learning merupakan konsep belajar mengajar yang dapat dilakukan oleh mahasiswa dimana saja dan kapan saja. E-learning sendiri juga dapat mengembangkan kemandirian mahasiswa seperti pada pemahaman materi pembelajaran melalui soal-soal kuis yang nantinya di kumpulkan menjadi bank soal [1]. Universitas yang sudah menerapkan e-learning salah satunya adalah Universitas Telkom dalam proses belajar mengajarnya. Salah satu program studi di Universitas Telkom yaitu S1 Sistem Informasi memiliki mata kuliah wajib yaitu Data Warehouse dan Business Intelligence (DWBI). Dari mata kuliah tersebut terdapat beberapa materi topik seperti Business Intelligence, Data Warehouse, Data Analitik, dan Pengukuran Kinerja . Dengan banyaknya topik yang dipelajari beberapa mahasiswa terkadang sulit memahami materi yang diberikan dosen Mata Kuliah tersebut. Hal tersebut membuat mahasiswa sulit untuk mencari jawaban dari soal kuis dengan topik yang berbedabeda. Maka dari itu, dibutuhkan sistem yang dapat melakukan klasifikasi kategori topik soal secara otomatis dan sistematis. Dengan harapan sistem tersebut nantinya akan mempermudah para mahasiswa mencari jawaban soal kuis tanpa melihat semua topik yang telah diajarkan melalui platform $e$ learning [2]. Sistem ini juga diharapkan dapat mempermudah para dosen pengampu dalam mengukur mahasiswa dalam menjawab soal kuis, berdasarkan pemahaman topik atau materi yang telah diajarkan.

Banyak pendekatan yang dilakukan untuk membuat question classification, dan memperoleh hasil yang wajar. Salah satu cara yang dapat dilakukan dalam klasifikasi soal berdasarkan kategori topik secara otomatis yaitu dengan menggunakan pendekatan machine learning. Dari beberapa metode pada machine learning yang cocok digunakan dalam question classification ini yaitu Natural Language Processing (NLP). NLP merupakan upaya untuk mengekstrak representasi lebih lanjut dari teks bebas, tujuan dari NLP sendiri untuk membuat model perhitungan Bahasa sehingga manusia dengan komputer dapat berinteraksi melalui perantara bahasa alami [3]. NLP juga dapat digunakan konsep bahasa seperti kata benda dan kata sifat [4]. Dengan menggunakan pendekatan ini serangkaian soal kuis dimasukkan terlebih dahulu ke dalam pengklasifikasian berdasarkan topik soal kuis mata kuliah DWBI [5]. Pada metode machine learning terdapat beberapa algoritma, pada penelitian ini digunakan algoritma Nä̈veBayes dan Support Vector Machine dalam klasifikasi soal kuis berdasarkan topik. Perbandingan dilakukan dengan mengukur akurasi kedua algoritma menggunakan pendekatan Cross Validation. Metode ini digunakan apabila data yang dimiliki terbatas [6].

Berdasarkan penelitian jurnal yang berjudul "Question Classification using Machine Learning Approaches" dengan algoritma yang digunakan yaitu Nä̈ve Bayes Classifier dan Support VectorMachine, dinyatakan bahwa pengklasifikasian menggunakan algoritma Nä̈ve Bayes memiliki kesederhanaan dan sangat populer karena memiliki komputasi yang efisien dan kinerja yang sangat bagus dalam menyelesaikan masalah pada dunia nyata. Hasil percobaan pada penelitian tersebut juga menyatakan algoritma Support Vector 
Available online at http://jurnal.stmikroyal.ac.id/index.php/jurteksi

Machine secara konsisten mempunyai kinerja yang baik pada klasifikasi pertanyaan, mengungguli algoritma Nä̈ve Bayes [7]. Sedangkan pada penelitian lain yang berjudul "Topic Classification of Islamic Question and Answer Using Naïve Bayes Classifier" menyatakan algoritma Nä̈ve Bayes dengan nilai akurasi 0,97 dapat digunakan untuk klasifikasi pertanyaan ", [8]. Sehingga jurnal yang dibuat bermaksud membandingkan hasil klasifikasi serta akurasi pada soal kuis mata kuliah DWBI menggunakan algoritma machine learning yaitu Nä̈ve Bayes dan Support Vector Machine.

\section{METODE}

Penelitian ini dikerjakan dengan menggunakan pendekatan machine learning dengan perhitungan akurasi algoritma menggunakan cross-validation. Tahapan penelitian ditunjukkan pada Gambar 1, dan selanjutnya menjelaskan masing-masing tahapan yang dilakukan.

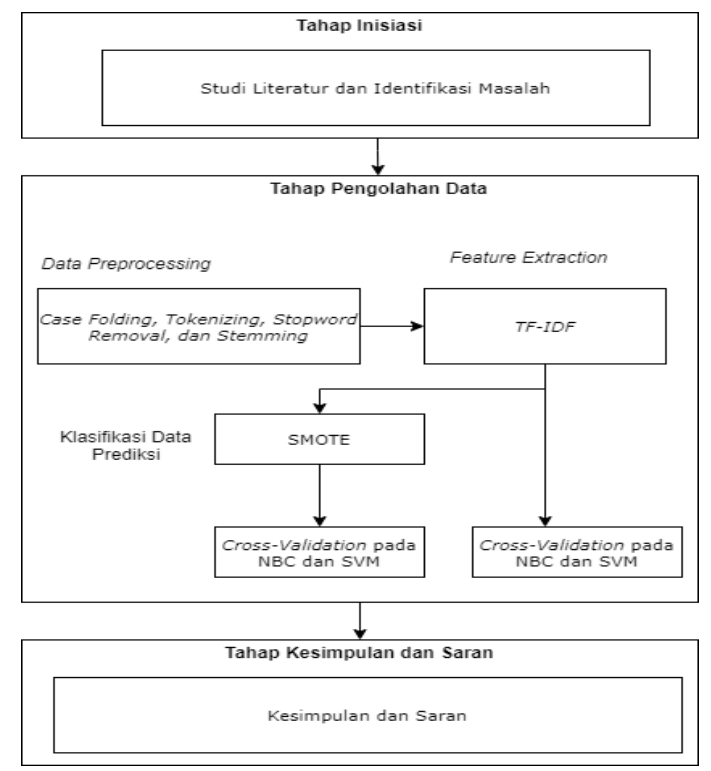

Gambar 1 Sistematika Penulisan
Tahap yang dilakukan pertama pada penelitian ini yaitu melakukan studi literatur serta identifikasi masalah mengenai klasifikasi pertanyaan berdasarkan kategori topik soal otomatis, sehingga dapat memudahkan mahasiswa dalam menjawab soal kuis, dan memahami materi atau topik yang dipelajari [9]. Metode yang digunakan yaitu dengan membandingan hasil akurasi dari algoritma klasifikasi machine learning, seperti Nä̈veBayes dan Support Vector Machine. Selanjutnya, peneliti melakukan pengumpulan data - data untuk dijadikan dataset dan pemberian label berdasarkan topik pada setiap soal. Data yang digunakan adalah soal kuis mata kuliah Data Warehouse dan Business Intelligence. Berkas tersebut merupakan kumpulan data kuis dari empat kelas mahasiswa S1 Sistem Informasi Telkom University Angkatan 2018 yang telah diekstrak dan disimpan kedalam Google Drive dengan masingmasing kelas memiliki 11 file excel yang sama, berdasarkan jumlah materi yang diberikan. Dari semua data yang sudah didapat menggabungkannya menjadi satu sehingga memperoleh jumlah soal sebanyak 3135 soal kuis. Soal kuis tersebut kemudian dilakukan pemilahan untuk menghilangkan data duplikat dan data tidak relevan, dari hasil pemilahan data tersebut diperoleh jumlah soal sebanyak 160 soal kuis. Sebelas file excel tadi diolah lagi menjadi empat topik yang lebih luas lagi seperti, Business Intelligence, Data Warehouse, Data Analitik, dan Pengukuran Kinerja yang dapat ditunjuk pada Tabel 1. 
Tabel 1. Labelling

\begin{tabular}{cc}
\hline Soal & Label \\
\hline $\begin{array}{c}\text { Fokusnya terhadap Enterprise/Executive IS adalah } \\
\text { sejarah business intelligence pada tahun }\end{array}$ & Business Intelligence \\
\hline $\begin{array}{c}\text { Data terorganisir berdasarkan subjectnya yaitu } \\
\text { pengertian karakteristik data warehouse berupa }\end{array}$ & Data Warehouse \\
\hline $\begin{array}{c}\text { Jenis KPI yang menjelaskan target diberikan kerangka } \\
\text { waktu yang harus dipenuhi adalah }\end{array}$ & Pengukuran Kinerja \\
\hline $\begin{array}{c}\text { Big data challenge yang Kemampuan untuk } \\
\text { memproses data dengan cepat, seperti yang ditangkap } \\
\text { adalah }\end{array}$ & Data Analitik \\
\hline
\end{tabular}

Tahap dari pengolahan data yang selanjutnya yaitu Data Preprocessing. Preprocessing merupakan Teknik untuk mengubah teks menjadi data yang siap diolah yang bertujuan untuk menghilangkan noise, dan mengambil fitur penting pada sebuah teks. Tahapan yang dilakukan pertama kali dalam Preprocessing yaitu Casefolding. Casefolding itu merupakan langkah yang dilakukan untuk ubah semua huruf yang terdapat pada suatu dokumen teks semua huruf kecil,[10]. Setelah selesai melakukan tahap case folding, peneliti melakukan tokenizing yang merupakan proses pemecahan kalimat menjadi bagian seperti token [10]. Tahap selanjutnya yaitu stopword removal yang merupakan proses menghilangkan kata-kata yang tidak mengandung makna [11], [12]. Langkah terakhir pada tahapan preprocessing yaitu stemming dengan mengembalikan katakata ke dalam bentuk kata dasarnya dengan cara menghapus imbuhan awal, akhir, atau kedua-duanya [13].

Tahapan selanjutnya yaitu pada penghitungan bobot kata pada dokumen yaitu TF-IDF [14]. Kemudian dilakukan klasifikasi dan prediksi data dengan menerapkan algoritma Naïve Bayes dan Support Vector Machine dengan metode SMOTE dan Cross-Validation untuk menghitung performa kedua algoritma tersebut. SMOTE merupakan salah satu solusi yang diusulkan untuk menangani data yang tidak seimbang atau data imbalance. SMOTE dapat membuat data manual, kelas kecil setara dengan kelas mayor [15],[16]. Algoritma Naïve Bayes bertujuan untuk menemukan nilai probabilitas tertinggi pada data testing [17]. Secara umum untuk rumus teorema bayes yang digunakan

$P(C \mid X)=\frac{P(X \mid C) P(C)}{P(X)}$

Keterangan:

$\mathrm{P}(\mathrm{C} \mid \mathrm{X})$ : Diberikan sebuah fakta atau rekaman $\mathrm{X}, \quad$ asumsikan probabilitas $\mathrm{Ci}$

$\mathrm{P}(\mathrm{X} \mid \mathrm{C}) \quad$ : Menemukan nilai parameter yang memberikan probabilitas terbesar

$\mathrm{P}(\mathrm{C}) \quad$ : Probabilitas sebelumnya dari $\mathrm{X}$

$\mathrm{P}(\mathrm{X}) \quad$ : jumlah tupel probabilitas kemunculan

Selain algoritma Nä̈veBayes, algoritma klasifikasi Support Vector Machine juga merupakan algoritma yang meraih kesuksesan besar pada berbagai masalah klasifikasi [18]. Dalam pemodelan matematisnya SVM diberi poin $\mathrm{N}$ dari pertanyaan dalam data training 
Available online at http://jurnal.stmikroyal.ac.id/index.php/jurteksi

$$
\left\{x_{i}, y_{i}\right\}_{i=1}^{N}
$$

di mana:

$x_{i}=$ input ke- $i$

$y_{i}=$ output label kelas ke- $i$

Persamaan kernel linear SVM dapat ditulis sebagai berikut [19] :

$$
f(x)=\operatorname{sign}\left[\sum_{i=1}^{n} \alpha_{i} y_{i} \theta\left(x, \chi_{i}\right)+b\right][3]
$$

di mana:

$$
n=\text { nomor support vectors }
$$

$x_{i}=$ pola pertanyaan ke- $i$

$y_{i}=$ label kelas pertanyaan ke- $i$

$\theta\left(x, \chi_{i}\right) \quad=$ fungsi kernel linier

Penggunaan flip terbaik adalah melakukan verifikasi 10 kali lipatan dalam model. Gambar 2 merupakan contoh proses 10fold pembagian dataset menggunakan cross-validation. Cara Kerja Crossvalidation yaitu total instance dibagi menjadi $\mathrm{N}$ bagian, ketika bagian pertama data testing dilipat dan sisanya menjadi data latih, begitu seterusnya hingga fold ke-10 [20].

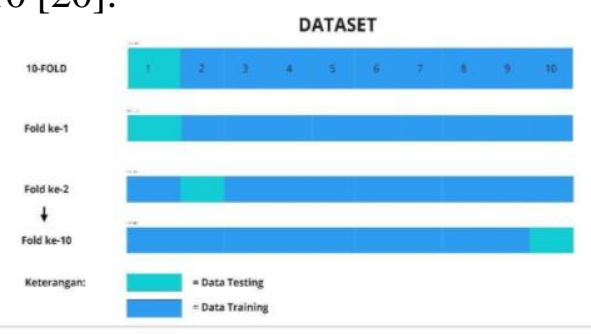

Gambar 2. Cross-Validation
Selanjutnya, menghitung berdasarkan keakuratan bagian ini dari data. Akurasi dihitung menggunakan persamaan:

Akurasi $=$ $\underline{\Sigma \text { data testing klasifikasi benar }} \times 100$ [4] stotal data testing

Setelah mendapatkan hasil perbandingan akurasi dilakukan evaluasi model. Kesimpulan dilakukan untuk merangkum semua hasil yang sudah dibahas pada penelitian ini, serta memberikan saran sebagai bahan pertimbangan untuk evaluasi penelitian selanjutnya.

\section{HASIL DAN PEMBAHASAN}

Data preprocessing dilakukan melalui banyak tahap agar data tersebut dapat diterima atau digunakan oleh model. Tabel 2 merupakan hasil data preprocessing pada tahap pengolahan data.

Setelah melalui tahap preprocessing masuk kedalam TF-IDF pada tahap ini setiap kata pada dokumen diperhitungkan nilai bobotnya. Perhitungan bobot diambil dari hasil stemming yang dapat dilihat pada Tabel 3:

Tabel 2. Preprocessing

\begin{tabular}{cc}
\hline Preprocessing & Hasil Preprocessing \\
\hline ebelum Preprocessing & $\begin{array}{r}\text { Aktor yang bertanggung jawab atas analisis prediktif, analisis statistik, dan } \\
\text { tools analitik yang lebih canggih serta algoritmanya adalah }\end{array}$ \\
\hline Case Folding & $\begin{array}{r}\text { aktor yang bertanggung jawab atas analisis prediktif, analisis statistik, dan } \\
\text { tools analitik yang lebih canggih serta algoritmanya adalah }\end{array}$ \\
\hline Tokenizing & $\begin{array}{r}\text { ['aktor', 'yang', 'bertanggung', 'jawab', 'atas', 'analisis', 'prediktif', 'analisis', } \\
\text { 'statistik', 'dan', 'tools', 'analitik', 'yang', 'lebih', 'canggih', 'serta', } \\
\text { 'algoritmanya', 'adalah'] }\end{array}$ \\
\hline Stopword Removal & ['aktor', 'bertanggung', 'analisis', 'prediktif', 'analisis', 'statistik', 'tools', \\
'analitik', 'canggih', 'algoritmanya']
\end{tabular}


Available online at http://jurnal.stmikroyal.ac.id/index.php/jurteksi

Tabel 3. TF-IDF

\begin{tabular}{cc}
\hline Preprocessing & TF-IDF \\
\hline 'aktor' & 0.25774284640746975 \\
\hline 'tanggung' & 0.25774284640746975 \\
\hline 'analisis' & 0.44924955927307797 \\
\hline 'prediktif' & 0.25774284640746975 \\
\hline 'statistik' & 0.21396314349462084 \\
\hline 'tools' & 0.21396314349462084 \\
\hline 'analitik' & 0.22462477963653898 \\
\hline 'canggih' & 0.25774284640746975 \\
\hline 'algoritmanya' & 0.25774284640746975 \\
\hline
\end{tabular}

Sebelum masuk ke dalam perhitungan akurasi, menyeimbangkan dataset yang tidak seimbang jumlahnya menggunakan SMOTE dimana label Data Warehouse berjumlah 72 soal, Business Intelligence berjumlah 44 soal, Data Analitik 30 soal dan terakhir pelabelan mengenai pengukuran kinerja berjumlah 15 soal, seperti yang dapat kita lihat pada Gambar 3.

Setelah dilakukan tahap SMOTE data tersebut akan menjadi seimbang seperti pada Gambar 4 yaitu dengan mengikuti kelas mayoritasnya yaitu 72 buah soal.

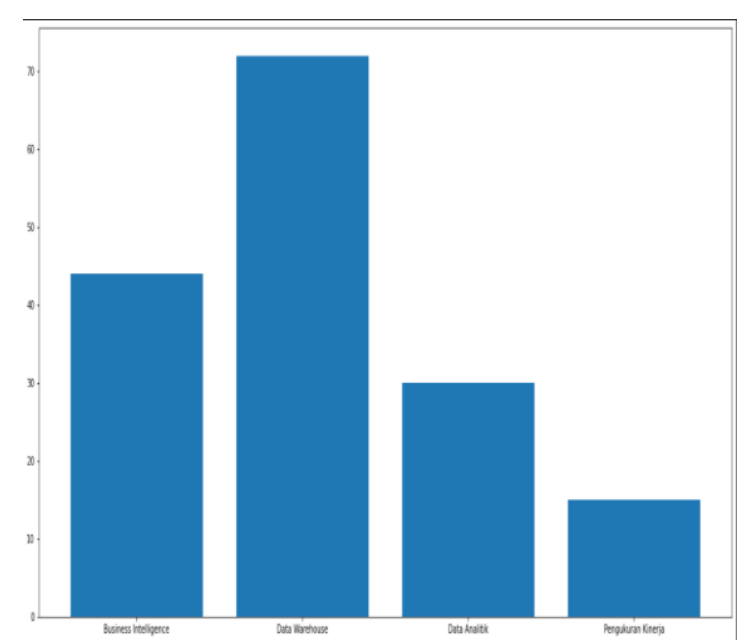

Gambar 3. Sebelum SMOTE

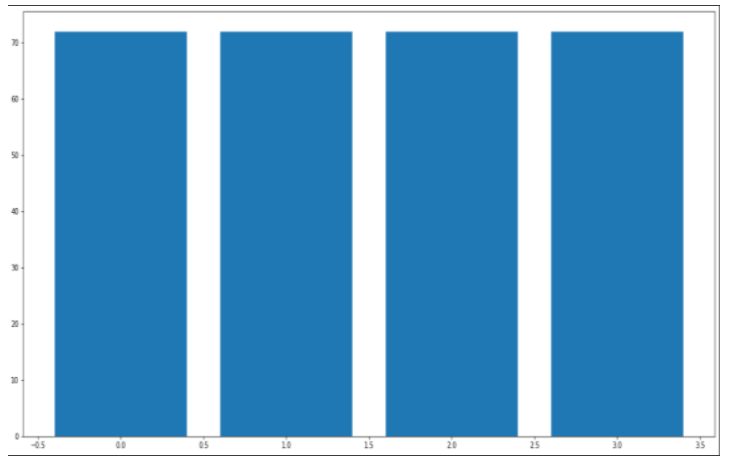

Gambar 4. Sesudah SMOTE

Selanjutnya, akan dilakukan perhitungan akurasi menggunakan metode Cross Validation. Pada tahap ini menggunakan 2 algoritma untuk mengetahui perbandingan akurasi menggunakan metode cross-validation ini. Gambar 5 merupakan hasil perbandingan akurasi algoritma Nä̈veBayes dan algoritma SupportVector menggunakan metode cross-validation.

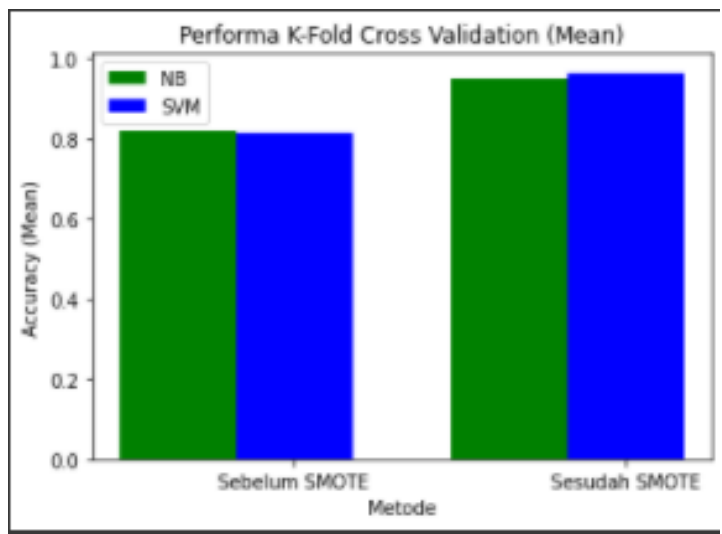

Gambar 5. Perbandingan Akurasi

Dari penerapan tersebut diperoleh perbandingan rata-rata skor pada algoritma Nä̈ve Bayes sebelum dilakukan SMOTE sebesar $82.02 \%$ dan sesudah SMOTE $94.79 \%$ sedangkan pada algoritma SVM rata-rata skor sebelum SMOTE sebesar $81.39 \%$ dan sesudah SMOTE 96.52\%. Berdasarkan persentase skor yang diperoleh, maka hasil skor metode cross validation ini masuk ke dalam klasifikasi yang baik. 
Available online at http://jurnal.stmikroyal.ac.id/index.php/jurteksi

\section{SIMPULAN}

Klasifikasi soal ini memberikan manfaat bagi Prodi S1 Sistem Informasi Telkom University dalam membantu pengambilan keputusan yang tepat dalam menentukan jenis soal berdasarkan kategori topik secara otomatis khususnya pada mata kuliah Data Warehouse dan Business Intelligence. Kesimpulan di dapat dari hasil analisis dimana pendekatan algoritma NaïveBayes dan algoritma SupportVectorMachine menggunakan metode SMOTE dan Cross-Validation melakukan kinerja yang bagus dalam klasifikasi soal berdasarkan kategori topik.

\section{DAFTAR PUSTAKA}

[1] Suharyanto and adele B. L. Mailangkay, "Penerapan ELearning Sebagai Alat Bantu Mengajar Dalam Dunia Pendidikan," J. Ilm. Widya, vol. 3, pp. 17-21, 2016, doi: 10.1016/j.neubiorev.2016.02.001.

[2] G. Tika and Adiwijaya, "Klasifikasi Topik Berita Berbahasa Indonesia Menggunakan Multilayer Perceptron," $e$ Proceeding Eng., vol. 6, no. 2, p. 2137, 2019.

[3] N. K. Wangsanegara and B. Subaeki, "IMPLEMENTASI NATURAL LANGUAGE PROCESSING DALAM PENGUKURAN KETEPATAN EJAAN YANG DISEMPURNAKAN (EYD) PADA ABSTRAK SKRIPSI MENGGUNAKAN ALGORITMA FUZZY LOGIC," J. Tek. Inform., vol. 8, no. 2, 2015, doi: 10.15408/jti.v8i2.3185.
[4] A. Aninditya, M. A. Hasibuan, and E. Sutoyo, "Text Mining Approach Using TF-IDF and Naive Bayes for Classification of Exam Questions Based on Cognitive Level of Bloom's Taxonomy," in 2019 IEEE International Conference on Internet of Things and Intelligence System (IoTaIS), 2019, pp. 112117.

[5] S. F. Kusuma, D. Siahaan, and U. L. Yuhana, "Automatic Indonesia's questions classification based on bloom's taxonomy using Natural Language Processing a preliminary study," in 2015 International Conference on Information Technology Systems and Innovation, ICITSI 2015 Proceedings, 2016, doi: 10.1109/ICITSI.2015.7437696.

[6] H. SITEFANUS, "ANALISIS KINERJA METODE CROSS VALIDATION DAN KNEAREST NEIGHBOR DALAM KLASIFIKASI DATA," pp. 7-37, 2020.

[7] A. DPanicker, A. U, and S. Venkitakrishnan, "Question Classification using Machine Learning Approaches," Int. J. Comput. Appl., vol. 48, no. 13, pp. 1-4, 2017, doi: 10.5120/74050101.

[8] N. F. Hardifa and K. M. Lhaksmana, "Topic Classification of Islamic Question and Answer Using Naive Bayes Classifier," vol. 4, no. August, pp. 199-204, 2019, doi: 10.21108/indojc.2019.4.2.346.

[9] A. Anika, M. H. Rahman, S. Islam, A. S. Mohammad Mahdee Jameel, and C. R. Rahman, "A Comprehensive Comparison of Machine Learning Based Methods Used in Bengali Question 
Classification,” 2019 IEEE Int. Conf. Signal Process. Information, Commun. Syst. SPICSCON 2019, pp. $\quad 82-85, \quad 2019, \quad$ doi: 10.1109/SPICSCON48833.2019.90 65107.

[10] D. Juang, "Analisis Spam dengan Menggunakan Naïve Bayes," J. Teknovasi, vol. 3 , no. 2 , pp. 51-57, 2016.

[11] I. R. Vanani, "Text analytics of customers on twitter: Brand sentiments in customer support," $J$. Inf. Technol. Manag., vol. 11, no. 2, pp. 43-58, 2019, doi: 10.22059/JITM.2019.291087.2410.

[12] E. Sutoyo and A. Almaarif, "Twitter sentiment analysis of the relocation of Indonesia's capital city," Bull. Electr. Eng. Informatics, vol. 9, no. 4, pp. 1620-1630, 2020.

[13] D. Rustiana and N. Rahayu, Analisis Sentimen Pasar Otomotif Mobil: $\quad$ Tweet Twitter Menggunakan Nä̈ve Bayes, vol. 8, no. 1. 2017.

[14] B. Herwijayanti, D. E. Ratnawati, and L. Muflikhah, "Klasifikasi Berita Online d engan menggunakan Pembobotan TF-IDF dan Cosine Similarity," vol. 2, no. 1, pp. 306-312, 2018.

[15] S. Maldonado, J. López, and C. Vairetti, "An alternative SMOTE oversampling strategy for highdimensional datasets," Appl. Soft Comput. J., vol. 76, pp. 380-389, 2019 , doi: 10.1016/j.asoc.2018.12.024.

[16] E. Sutoyo and M. A. Fadlurrahman, "Penerapan SMOTE untuk Mengatasi
Imbalance Class dalam Klasifikasi Television Advertisement Performance Rating Menggunakan Artificial Neural Network," JEPIN (Jurnal Edukasi dan Penelit. Inform., vol. 6, no. 3, pp. 379-385.

[17] M. M. Saritas and A. Yasar, "Performance Analysis of ANN and Naive Bayes Classification Algorithm for Data Classification," Int. J. Intell. Syst. Appl. Eng., vol. 7, no. 2, pp. 88-91, Jun. 2019, doi: 10.18201//ijisae.2019252786.

[18] A. Handayanto, K. Latifa, N. D. Saputro, and R. R. Waliansyah, "Analisis dan Penerapan Algoritma Support Vector Machine (SVM) dalam Data Mining untuk Menunjang Strategi Promosi," JUITA J. Inform., vol. 7, no. 2, p. 71, 2019, doi: 10.30595/juita.v7i2.4378.

[19] L. Demidova, E. Nikulchev, and Y. Sokolova, "Big Data Classification Using the SVM Classifiers with the Modified Particle Swarm Optimization and the SVM Ensembles," Int. J. Adv. Comput. Sci. Appl., vol. 7, no. 5, pp. 294312, 2016, doi: 10.14569/ijacsa.2016.070541.

[20] O. Ghorbanzadeh, H. Rostamzadeh, T. Blaschke, K. Gholaminia, and J. Aryal, "A new GIS-based data mining technique using an adaptive neuro-fuzzy inference system (ANFIS) and kfold cross-validation approach for land subsidence susceptibility mapping," Nat. Hazards, vol. 94, no. 2, pp. 497-517, 2018, doi: 10.1007/s11069-018-3449-y. 